\title{
Thermoplastic shear localisation in titanium alloys during dynamic deformation
}

\author{
Y. B. Xu, L. Liu, J. O. Yu, L. T. Shen, and Y. L. Bai
}

Cylindrical specimens ( $4 \mathrm{~mm}$ diameter and $4 \mathrm{~mm}$ height) of titanium alloy bar were given various heat treatments to provide a wide range of microstructures and mechanical parameters. These specimens were then subjected to high plastic strain at a large strain rate $\left(10^{3} \mathrm{~s}^{-1}\right)$ during dynamic compression by a split Hopkinson bar at ambient temperature. The microstructures of the localised shear bands were examined by optical and transmission electron microscopy. The results show that there are two types of localised shear bands: deformed and white shear bands. A detailed observation reveals that there is no difference in the nature of the deformed and white shear bands, but they occur at different stages of localised deformation. It is found that there is a burst of strain, corresponding to a critical strain rate at which the white shear band occurs and no phase transformation occurs in the shear bands.

MST/4420

Professor Xu, Dr Liu, and Dr Yu are in the State Key Laboratory for Fatigue and Fracture of Materials, Institute of Metal Research, Chinese Academy of Science, Shenyang 110015, China. Professor Shen and Professor Bai are in the Mechanics of Continuous Media, Institute of Mechanics, Chinese Academy of Sciences, Beijing 110080, China, where Professor Xu is also affiliated. Manuscript received 21 July 1999; accepted 20 January 2000.

(C) 2000 IoM Communications Ltd.

\section{Introduction}

There has been increasing interest in the formation and microstructure of shear deformation localisation since it was first recognised by Zener and Hollomon ${ }^{1}$ in 1944. Based on the qualitative analysis of Recht, ${ }^{2}$ Culver, ${ }^{3}$ Staker, ${ }^{4}$ Bai, ${ }^{5} \mathrm{Wu}$ and Freund, ${ }^{6}$ and Fressergeas and Molinari, ${ }^{7}$ scientists in mechanics have worked on the macrodescription of the constitutive model, proposing the criterion for the plastic deformation instability. However, scientists in metallurgy and materials science have focused their efforts on the relationship between shear localisation and microstructural evolution, exploring the role of localised shear in engineering applications. Comparatively, the studies of this aspect are not systematic, and there is still controversy concerning the microstrutural aspects such as phase transformation and recrystallisation, as well as the effect of material parameters on the localised shear deformation, etc.

The present paper describes an investigation of the formation and microstructure of the shear localisation occurring during dynamic loading in a titanium alloy.

\section{Materials and procedure}

The alloy used in the present study has a chemical composition (wt- $\%$ ) of $\mathrm{Ti}-4 \cdot 0 \mathrm{Al}-2 \cdot 0 \mathrm{Zr}-1 \cdot 0 \mathrm{Mo}-0 \cdot 8 \mathrm{Nd}-$ $0 \cdot 25 \mathrm{Sn}$. The material was subjected to the following treatments:

(i) $1 \mathrm{~h}$ holding at $900^{\circ} \mathrm{C}$ followed by air cooling, and then $2 \mathrm{~h}$ at $600^{\circ} \mathrm{C}$ followed by air cooling

(ii) $1 \mathrm{~h}$ at $1040^{\circ} \mathrm{C}$ followed by quenching in water, and then $2 \mathrm{~h}$ at $600^{\circ} \mathrm{C}$ followed by air cooling.

The specimen used in dynamic compression testing was a cylinder with a diameter of $4.0 \mathrm{~mm}$ and height of $4.0 \mathrm{~mm}$.

The high speed dynamic compression tests were performed on the as received and heat treated materials (see Table 1) in a split Hopkinson bar with an average strain rate of $10^{4} \mathrm{~s}^{-1}$. The microstructural evolution of the localised shear bands was characterised by optical and transmission electron microscopy.

\section{Results and discussion}

\section{TOPOGRAPHY}

There are two types of shear bands with different appearances, the deformed and white shear bands, that are easily recognised in all three alloys tested as shown in Table 1. The white shear bands presented here are currently referred to as the transformed bands, depending on whether or not a phase transformation is presumed to have occurred during dynamic deformation. ${ }^{8-13}$ This kind of band and its microstructure have been the focus of many studies because it is proposed that a high temperature may be reached in the narrow band of material, which in turn supports the thermomechanical instability theory of adiabatic shear banding. ${ }^{14}$

A number of observations in the present study indicate that there is no phase transformation observed even in the white shear bands. In other words, both the deformed and white shear bands form at different stages of localised deformation; the deformed shear bands appear first, and then the white shear bands occur as a consequence of further development of the deformed shear bands. Giovanola $^{14}$ has pointed out that the transformation bands often, but not always, develop within the deformed bands, and their presence on metallographic cross-sections is usually indicated by a different etching response in a narrow band of material. Observations made in the present study are in good agreement with this result ${ }^{14}$ and results from work on Al-Li alloys. ${ }^{15}$

\section{CRITICAL STRAIN RATE}

The shear localisation behaviour in all three alloys, shows the same characteristic trends. As the strain rate increases,

Table 1 Critical strain rates for formation of white shear bands in given alloys

\begin{tabular}{lll}
\hline & Critical strain rate, & $\begin{array}{l}\text { Width of band, } \\
\mu \mathrm{m}\end{array}$ \\
\hline Alloy & $10^{3} \mathrm{~s}^{-1}$ & 10 \\
As received material & 2.00 & 9 \\
$\alpha+\beta$ region & 1.85 & 6 \\
$\beta$ region & 1.30 & \\
\hline
\end{tabular}




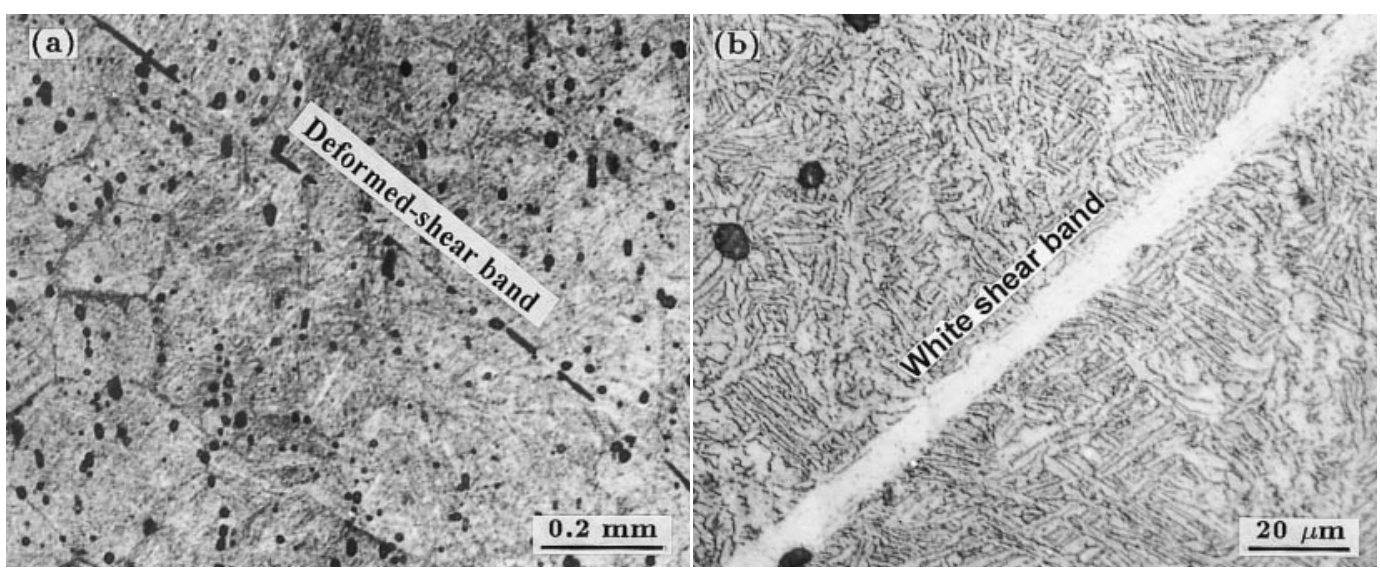

1 a deformed shear band and $b$ white shear band in Ti alloy
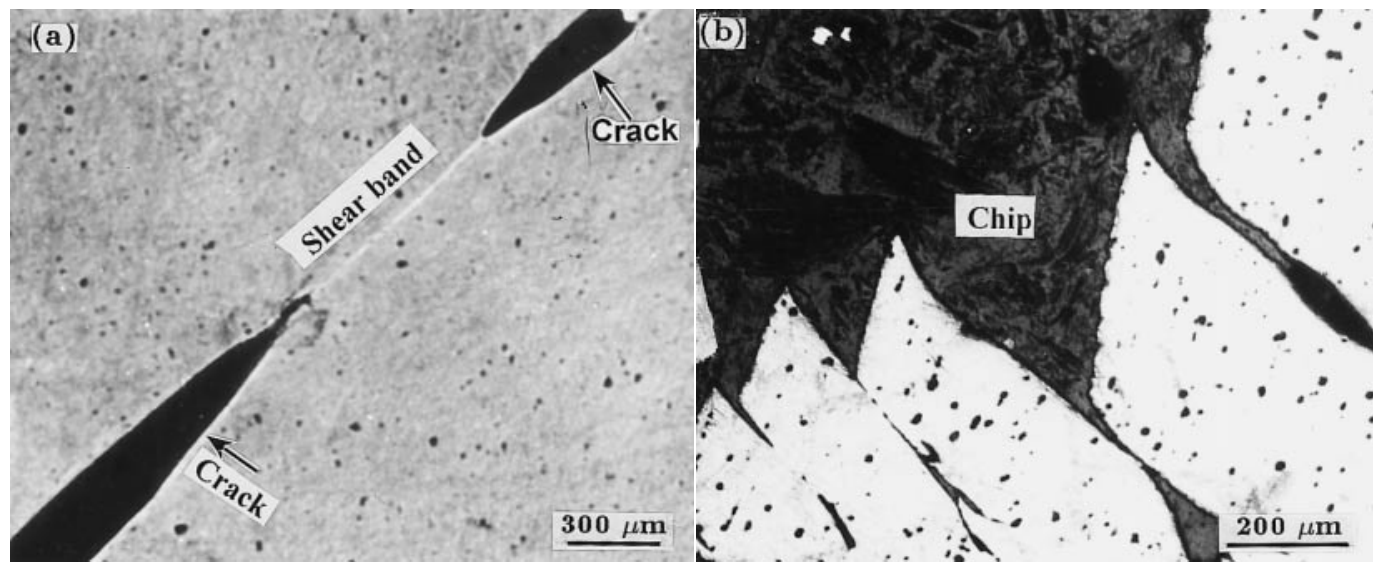

2 a elliptical cracks along shear band and $b$ chips produced during dynamic loading of $\mathrm{Ti}$ alloy

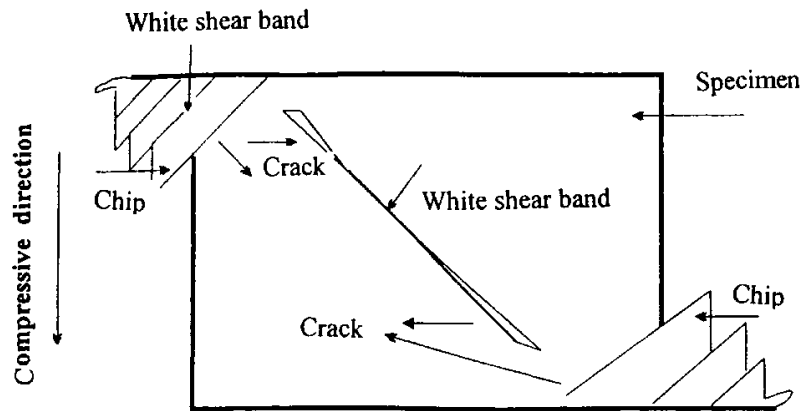

3 Schematic diagram for formation of bands, cracks, and chips during dynamic loading

localised deformation develops gradually. When the strain rate reaches $1.75 \times 10^{3} \mathrm{~s}^{-1}$, the deformed shear bands appear first, and as deformation proceeds, the width of the band becomes gradually narrower, and microcracks appear along the bands as shown in Fig. $1 a$. When the strain rate is approximately $2.0 \times 10^{3} \mathrm{~s}^{-1}$, the white shear bands occur as a result of the further development of the deformed shear bands as shown in Fig. $1 b$. At this moment, elliptical cracks appear along the band as shown in Fig. $2 a$, and also some chips form at the upper and lower surfaces of the cylindrical specimen, which is in contact with the bars, as the strain rate increases (see Fig. 2b).

Based on the above observations, it is reasonable to propose a model describing all the events that occur during dynamic loading as shown schematically in Fig. 3. Table 1 gives the critical strain rates required for the formation of the white shear bands. It can be seen that the value of the critical strain rate required for the white shear band

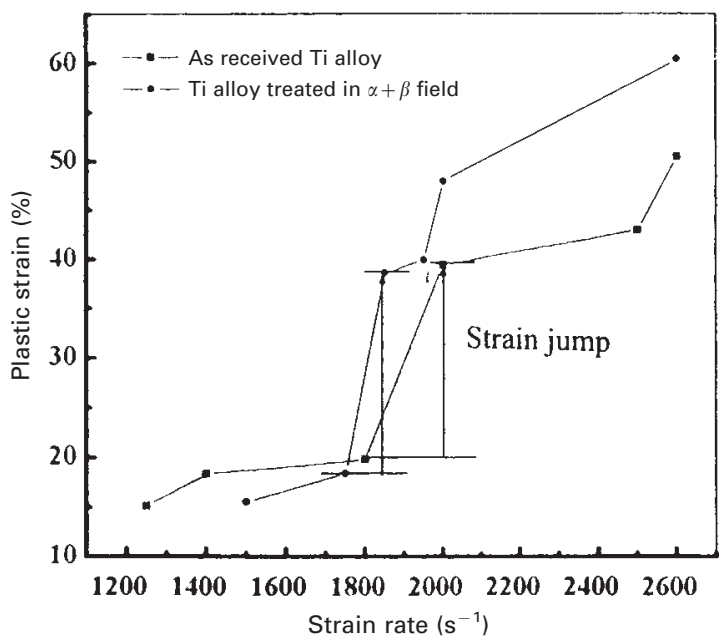

4 Strain jump occurring during dynamic loading in Ti alloy

formation in the as received alloy is higher than those of the other two alloys, and the higher the strength of the alloy with lower work hardening capability, the narrower the shear band is.

It is interesting to note that the occurrence of the white shear bands is accompanied with an abrupt increase in plastic strain as shown in Fig. 4, and this jump in plastic strain corresponds to the critical strain rate required for the formation of the white shear bands. It is expected that there is not only a large strain but also a high strain rate in the band when it forms during deformation. 


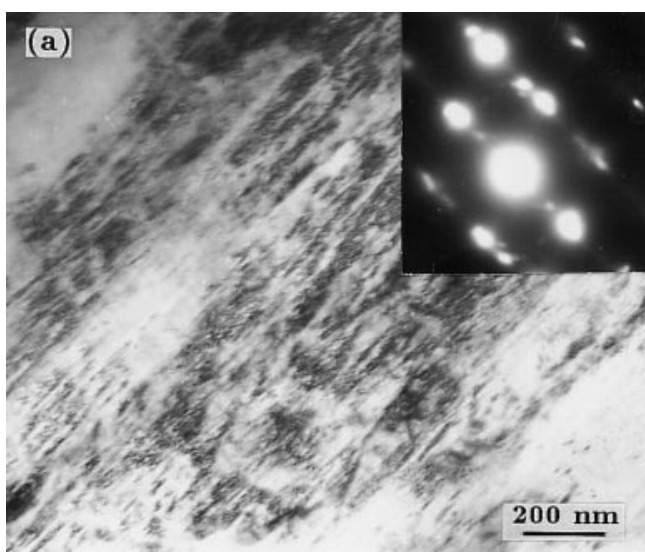

5 Deformation twins $a$ outside and $b$ inside band

\section{MICROSTRUCTURE}

One of the important deformation features obtained in the present study is shown in Fig. 5a, which shows a great deal of deformation twinning produced during high strain rate compression, both outside and inside the bands. It can be found that the difference in microstructure is that the twins in the band become nanosized substructures shown in Fig. $5 b$, which is the so called twin domain with an average size in the hundred nanometre range owing to the refinement and rotation of the twins, arising from a high accumulated plastic strain as the deformation proceeds. These domains with low angle boundaries tend to align along the shear direction. A number of observations show that there is no evidence for any phase transformation occurring in the three alloys in the present study.

\section{Conclusions}

1. Two types of shear bands, deformed and white shear bands, are currently observed in all three treated titanium alloys. The deformed band occurs first, and the white shear band is formed as a result of further development of the deformed bands.

2. There is a critical strain rate required for the formation of the shear bands. The value of the critical strain rate in the as received alloy is higher than those of the other two alloys.

3. Twinning is an important deformation mode under high strain rate loading, and the twin domains may occur owing to the large accumulated plastic strain in the bands. These domains with low angle boundaries tend to align along the shear direction in the alloys.

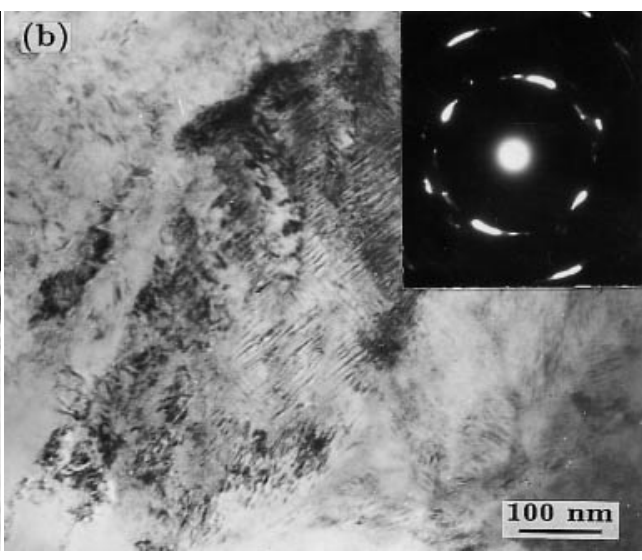

4. There is no evidence for any phase transformation occurring during the dynamic compression.

\section{Acknowledgement}

This work was supported by the National Science Foundation of China (NSFC) Grant No. 19891180-2 and subsidised by the Special Funds for the Major State Basic Research Projects G19990650

\section{References}

1. C. Zener and J. H. Hollomon: J. Appl. Phys., 1944, 15, 22.

2. R. F. RECHT: J. Appl. Mech. (Trans. ASME) E, 1964, 31, 189.

3. R. S. CULVER: Exp. Mech., 1972, 12, 393.

4. M. R. STAKER: Acta Metall., 1981, 29, 633.

5. Y. L. BAI: in 'Shockwaves and high strain rate phenomena', (ed. L. E. Murr and M. A. Meyers), 277; 1981, New York, Plenum. 6. F. H. WU and L. B. FReUnd: J. Mech. Phys. Solids, 1984, 32, 119.

7. C. Fressengeas and A. MOlinari: J. Mech. Phys. Solids, 1987, 35, 185.

8. J. H. ANDREWS, H. LEE, L. BOURNE, and D. V. WILSON: J. Iron Steel Inst., 1950, 165, 369.

9. H. O. MCINTIRE and G. K. MANNING: Met. Prog., 1958, 74, (5), 94

10. S. A. MANION and T. A. C. STOCK: Int. J. Fract. Mech., 1970, 6, 106.

11. R. L. WOODWARD and R. L. AGHAN: Met. Forum., 1978, 1, 180.

12. H. A. GREBE, H.-R. PAK, and M. A. MEYERS: Metall. Trans. A, 1985, 16A, 7619.

13. A. K. ZUREK: Metall. Trans. A, 1994, 25A, 2483.

14. J. H. GIOVANOLA: Mech. Mater., 1988, 7, 73.

15. W. L. ZHONG, Y. B. XU, L. T. SHEN, and y. L. BAI: Acta Metall. Sin. (China), 1999, 35, 384. 